\title{
La imagen de los Hombres de Campo: Relaciones de género racializadas en fotografías del Archivo General de la Nación (Argentina)*
}

Sergio Caggiano**

\section{Resumen}

El artículo analiza imágenes conservadas en el Archivo General de la Nación (Argentina), poniendo el foco en la composición de las fotografías y en la clasificación de los materiales. Interroga la construcción visual de una figura masculina emblemática de la nacionalidad, el gaucho u hombre de campo. Destaca dos rasgos principales: la domesticación de la naturaleza, presentada como potestad de los hombres, y la división generizada entre el espacio de la casa / rancho y el del campo abierto. Por otra parte, la domesticación de la naturaleza se muestra como una tarea blanca y civilizatoria.

Palabras clave: $\quad$ Fotografía, Archivo histórico, Género, Domesticación de la naturaleza.

\footnotetext{
* Recibido el 07 de abril de 2016, aceptado el 02 de marzo de 2018.

** Investigador en el Centro de Investigaciones Sociales (CIS) - CONICET/IDES, Buenos Aires, Argentina. sergio.caggiano@gmail.com
} 
The Image of the Men of Countryside: Racialized Gender Relations in Photographs of the General Archive of the Nation (Argentina)

\section{Abstract}

This article analyses images from the General Archive of the Nation (Argentina), focalizing on the photographs composition, and on the classification of materials. It wonders about the visual construction of a male emblematic national figure, the "gaucho" or "man of countryside". It highlights two main features: the domestication of nature, shown as attribute of men, and the gendered division between the home/rancho and the greenfield. Besides that, the domestication of nature is shown as a whiten and civilizing work.

Keywords: Photography, Historic Archive, Gender, Domestication of Nature. 


\section{Introducción}

A partir del interés en el carácter socialmente productivo de las imágenes fotográficas, y en el carácter también productivo de los archivos estatales, este artículo se originó en un trabajo en el Departamento de Documentos Fotográficos (DDF) del Archivo General de la Nación (AGN) de Argentina. ${ }^{1}$ Una inquietud general acerca de la lógica de género que organizaba los materiales del archivo y las composiciones de las fotografías decantó, con el correr de la investigación, en preguntas acerca de la construcción visual de una figura nacional emblemática, el gaucho u hombre de campo: ¿qué rasgos presentan las imágenes resguardadas por el AGN que componen esta figura emblemática?, ¿en qué lugares puede verse al hombre de campo?, ¿realizando cuáles actividades?, ¿qué otros actores/as lo acompañan?; ¿se distribuyen espacios sociales diferenciados para hombres y mujeres?

Realizaré en esta Introducción un breve repaso de la gestación de los interrogantes que el artículo atiende y referiré algunos puntos de partida teóricos y metodológicos para el análisis de las imágenes y de los archivos. A continuación, tras ofrecer algunos apuntes sobre el carácter emblemático de los "hombres de campo" en Argentina, describiré los principales hallazgos de la exploración en la sección del archivo que lleva su nombre, sección en la que concentré mi actividad, guiado por los avances de la investigación. Los posteriores apartados de análisis permitirán apreciar una racialización de la dimensión de género. Podrá verse que la masculinidad imaginada para los hombres de campo es civilizatoria y blanca.

\footnotetext{
1 Llevé adelante visitas sistemáticas al AGN entre marzo y agosto de 2008. Tras los primeros avances analíticos, realicé nuevas visitas durante 2011, 2013 y 2016. Además de la revisión etnográfica de su acervo (Gomes da Cunha, 2005), mantuve entrevistas con los encargados de la atención al público y con las jefas del DDF. Se trató de un trabajo en y con el archivo (Gomes da Cunha, 2005), es decir, una investigación que tomó al "archivo como tema" (Stoler, 2002:91).
} 


\section{La maduración de las preguntas}

En un trabajo anterior sobre la dimensión de género en paisajes visuales públicos contemporáneos, pude reconstruir el enfoque masculino y patriarcal en la prensa gráfica, en manuales escolares y en álbumes de fotografías históricas de circulación masiva, entre otros repertorios visuales hegemónicos (Caggiano, 2012). Las imágenes de hombres y mujeres se distribuyen en ellos de acuerdo con el eje calle/casa. ${ }^{2}$ Dependiendo de la clase social, los hombres se muestran en distintas posiciones del trabajo extradoméstico, en el frente de batalla, en las manifestaciones políticas o en las instituciones de gobierno. La calle misma o extensiones abiertas son contextos usuales de las tomas que los tienen como protagonistas. Las mujeres también difieren socialmente entre ellas, pero todas coinciden en su referencia a la privacidad del hogar. Se encargan del trabajo doméstico, en tanto que empleadas o como esposas, madres o hijas, y solo unas pocas se aproximan a la política, generalmente como representantes $\mathrm{O}$ apéndices de un hombre (hija de, esposa de). A la mujer le toca la casa y la casa le toca exclusivamente a la mujer. La casa no es, por lo demás, el lugar desde donde estos repertorios cuentan la historia. Antes bien, se trata de una historia mostrada a partir de los "acontecimientos políticos", y es a los varones a quienes se muestra ocupando las calles y los palacios de gobierno. ${ }^{3} \mathrm{La}$ mostración del espacio extradoméstico y público como lugar de la política constituye un tópico prioritario en las disputas visuales de género en Argentina (Caggiano, 2012), y es por ello que estudios históricos feministas insisten en poner de relieve a las mujeres haciendo política en las calles durante toda la historia del Estado nación (Barrancos, 2008).

\footnotetext{
2 Los términos "no designan simplemente espacios geográficos (...), sino sobre todo entidades morales, esferas de acción social, jurisdicciones éticas dotadas de positividad, dominios culturales" (DaMatta, 1997:15).

3 A propósito de la relevancia de la política en las calles en Argentina, puede consultarse Rinesi (1994), Sábato (1998) y Sigal (2006), entre otros.
} 
Estos primeros pasos motivaron la inmersión en el acervo fotográfico del AGN que, con alrededor de un millón de fotografías para consulta pública, constituye el principal repositorio al que medios de comunicación masiva, sitios de Internet, editoriales, curadores, etc. recurren como fuente privilegiada de imágenes históricas para la reconstrucción del pasado de la Argentina. Mi exploración buscaba, entonces, en principio, comprender si los materiales existentes, su ordenamiento y su clasificación se conectaban con el sesgo de género de los referidos repertorios visuales hegemónicos.

El primer elemento que llama la atención en el archivo es la escasa presencia de categorías sociales entre los temas que organizan su acervo. El Índice Temático clasifica los Fondos Públicos en cerca de setenta Temas, divididos a su vez en unos mil trescientos Subtemas. Revisado alfabéticamente, el índice puede provocarnos la misma sorpresa que la enciclopedia china "citada" por Borges. Así como los animales en ella se dividían en "pertenecientes al Emperador", "amaestrados", "lechones", "fabulosos", "incluidos en esta clasificación", etc. (Borges, 1989:86), el índice del DDF reúne "Aborígenes, Agricultura, Antigüedades, Arqueología, Asistencia Social, Autógrafos, Aviación Civil, Avicultura, Bailes, Bancos, Bellas Artes, Capital Federal, Científicas", etc. Observado mejor, podemos reconocer en sus nombres instituciones y áreas de actuación del Estado, actividades económicas, culturales, deportivas o religiosas, profesiones y oficios, circunscripciones geopolíticas, formas de representación social y política, geografía y zoología, etc. En cualquier caso, las categorías sociales, es decir, las que refieren a grupos o sectores sociales, son muy pocas, y esta escasez las vuelve particularmente significativas.

Me concentro aquí en una de ellas: el subtema Gauchos u Hombres de Campo, no solo por invitar desde su denominación a una indagación en clave de género, sino principalmente por tratarse de una figura emblemática, prototípica en este país, en los relatos acerca de su historia, su moral y sus costumbres. En las imágenes del AGN, los trazos constitutivos de esta figura, previsiblemente masculina, se recortan contra otras imágenes que 
lo acompañan, empezando por las de las mujeres. Pero además el análisis conducirá, en algunos pasajes, al contraste con otra de las categorías sociales, la cual da nombre a un Tema del Índice: Aborígenes, que permitirá iluminar algunos rasgos de aquella. ${ }^{4}$

Dos trazos principales convergen en la construcción visual del hombre de campo. Uno de ellos es la domesticación de la naturaleza. El otro, íntimamente relacionado, es la pertinaz división generizada de dos espacios: el de la casa o el rancho, por un lado, y el del campo abierto, por otro. Presentada como potestad y atributo de los hombres, la domesticación y el control de la naturaleza, no solo los caracteriza a ellos, sino también a las mujeres y a las relaciones entre hombres y mujeres. Pero además, la domesticación de la naturaleza, clave analítica e interpretativa, intersecta en las imágenes del AGN género y racialización, mostrándose como una tarea civilizatoria a cargo de hombres presuntamente blancos.

\section{Indagar imágenes en un archivo fotográfico}

Los archivos como el AGN ofrecen materiales para la imaginación ${ }^{5}$ de (el pasado de) la comunidad nacional. El archivo es un "artefacto cultural de producción de hechos" (Stoler, 2002:91). Si bien es obvio que los archivos "son producto de las máquinas estatales, es menos obvio que ellos son, por derecho

\footnotetext{
4 Una tercera categoría social que da nombre a otro Tema, Negros, transformada en 2016 en Afroamericanos, ha merecido un análisis no solo por las imágenes de lugares, objetos o símbolos que reúne, sino por su carencia casi absoluta de fotografías de personas (Caggiano, 2016). Existen otros pocos subtemas que son categorías sociales sueltas y no parecen concernir al sistema de clasificación social general como las otras tres: Ancianas, dentro del tema Asistencia Social, Pintores y Escultores, dentro de Bellas Artes, y Alienados, dentro de Salud Pública.

${ }^{5}$ El proceso de "imaginación social", en la acepción de Appadurai, combina la idea de imaginario o de representaciones en el sentido de Durkheim, la idea más habitual de las imágenes como producciones visuales concretas en diferentes soportes y la idea que está presente en usos adjetivados como el de "comunidad imaginada" de Benedict Anderson (Appadurai, 2001:44 y ss.).
} 
propio, tecnologías que sostienen la producción de los mismos estados" (Stoler, 2002:98). ${ }^{6}$ Es en virtud de este segundo aspecto que sus fondos y sus documentos parecen condensar "un núcleo indiscutible, sacralizado de formas de identificación de la comunidad nacional" (da Silva Catela, 2002:217), y es por ello que "los archivos no pueden ser vistos como simples repositorios de informaciones [...], sino como productores de identidades sociales" (Gomes da Cunha, 2002:32).

El papel de estos artefactos culturales en la producción de hechos (de "estados", de "comunidades nacionales", de "identidades sociales") toma aun mayor trascendencia al considerar que el archivo cautiva a su lector porque "produce en él la sensación de aprehender la realidad por fin" (Farge, 1989:14), sensación que, tratándose de un Departamento de Documentos Fotográficos, se duplica, puesto que la fotografía se caracteriza por su extendido uso social como "evidencia" (Vale de Almeida, 2000) y por el efecto de realidad que produce (Barthes, 1986; Schaeffer, 1990).

Analistas de las imágenes han advertido ya las numerosas formas en que ellas participan en la configuración de un sentido común políticamente cargado. El DDF del AGN reúne fotografías diversas en diferentes aspectos. Pero la realización de cualquiera de ellas ha debido acudir a un "idioma ritual" (Goffman, 1991). Allí reside gran parte de su valor analítico e histórico, en la medida en que dicho idioma ritual restituye a lo visual toda su densidad social. La estilización y ritualización de la mirada y de los modos de representar conecta con el poder y el control social, con la forma de mostrar quién puede ser o hacer determinada cosa

\footnotetext{
${ }^{6}$ Esta orientación general tiene importantes antecedentes en los trabajos de historia cultural de Zemon Davis (1987) o Trouillot (1995), por ejemplo, que han colocado en un lugar central las relaciones de poder de las que el archivo participa, y en nociones de "archivo" como las de Foucault (1991) o Richards (1993). Para una noción de archivo ligada a la fotografía, Sekula (1986) y DidiHuberman (2007).
} 
(Berger, 1972), con la división y distribución de espacios sociales y de quiénes pueden o deben ocuparlos (Smith, 1999; Poole, 2000).

A contrapelo de ese doble efecto de realidad del archivo y de la fotografía, aquí se trata de "leer" imágenes como resultado de una actividad de selección y creación, y leerlas en un archivo, que las agrupa y conecta -además de almacenarlas-, las organiza, acercándolas o alejándolas entre sí, las nombra y las describe. Esta lectura de las imágenes y de la lógica clasificatoria del archivo apunta a recuperar las modalidades de poder alrededor de las relaciones de género que exhiben las fotografías, las masculinidades y feminidades mostradas en la construcción de la figura emblemática del hombre de campo.

\section{El hombre de campo como emblema}

El DDF proviene del Archivo Gráfico de la Nación, creado en 1939 y absorbido por el AGN en 1957. El AGN tiene como criterio guardar el orden de procedencia, que implica no modificar la organización de un acervo cuando es recibido. En consecuencia, la mayoría de los temas y subtemas procede de la creación misma del archivo, o incluso del trabajo de organización previo a su inauguración, en la segunda mitad de la década de $1930 .{ }^{7}$ En esta época, transcurridas dos décadas desde las conferencias "El Payador" de Lugones (recopiladas y publicadas en 1916) y poco más de una de la publicación del Don Segundo Sombra de Güiraldes, el gaucho aparecía como paradigma de lo nacional, consolidado como expresión excelsa de la argentinidad, con un pasado redimido y un presente con tintes heroicos (Viñas, 1994).

Es innecesario argumentar acerca de la importancia que, desde entonces, tiene en Argentina el gaucho, que en tanto

\footnotetext{
${ }^{7}$ La inferencia sobre el origen de la clasificación y las categorías del DDF, basada en indicios léxicos, fue ratificada por ex funcionarios y funcionarios actuales del departamento (entrevistas del autor con Miryam Casals, responsable del DDF en mayo de 2008 y con Emilia Assali, responsable del DDF en octubre de 2016).
} 
símbolo se extiende como ningún otro a lo largo del territorio nacional y ha sido objeto de innumerables estudios (Viñas, 1994; Montaldo, 1993; Ludmer, 1994; Salvatore, 2003). Vale apuntar, no obstante, una particularidad del gaucho en relación con otras figuras emblemáticas nacionales o étnicas. La bibliografía especializada muestra que, a diferencia de lo que sucede en Argentina, en distintos lugares del mundo son símbolos femeninos los que encarnan el "carácter étnico" o "nacional tradicional" en peinados, vestimentas, accesorios y en su producción de los alimentos "típicos" (Heng y Devan, 1992; Radcliffe y Westwood, 1996; Derné, 2000). De acuerdo con estos trabajos, en la presentación pública de las mujeres y de algunos de sus quehaceres se consolidan rasgos pretendidamente "esenciales" de la pertenencia.

En Argentina es el hombre de campo o el gaucho quien viste y exhibe la indumentaria tradicional. Las prendas típicas del campo argentino son las de los varones (botas de potro, chiripá, rastra, poncho, sombrero y pañuelo, entre otras), y las precisiones de estilo, así como aquellas que permiten plasmar las distancias sociales y de clase se asocian a su atuendo, como podrá apreciarse en algunas imágenes (vgr. las fs. 15 a 17). También el caballo y sus aperos tendrán un lugar central para que cualquiera medianamente entendido pueda evaluar la calidad de lo "tradicional" que ha logrado materializarse en ellos. Además, como también podrá verse, son los hombres quienes son retratados preparando el asado, la comida reconocida y celebrada como el plato nacional por antonomasia (Archetti, 1999) y, en términos generales, preservando las tradiciones criollas.

En Argentina, entonces, los atavíos y accesorios "típicos" son los del hombre de campo -y los de su caballo-, no los de la mujer. El cuerpo del gaucho aparece como el cuerpo del campo argentino y, por ello, como uno de los cuerpos representativos de la nación. 


\section{Los hombres de campo y el campo de los hombres}

Referí al subtema en cuestión, ubicado dentro del tema Folklore, como Gauchos u Hombres de Campo. En rigor, son dos subtemas pero el primero contiene apenas un puñado de fotografías, y su ficha reenvía al segundo, que reúne su contenido junto a otros, resultando uno de los más extensos del DDF en lo que hace a cantidad de fichas. Evidentemente, en alguno de los reacomodos que se han dado en la historia del archivo, las fotografías de Gauchos pasaron a formar parte de Hombres de Campo, categoría más general.

El nombre Hombres de Campo actualiza una de las formas en que la generalización en masculino se vuelve categoría social. No existe el equivalente "mujer de campo" en el índice ni en el fichero del DDF (ni en el habla cotidiana en Argentina). Hombres de Campo remite a personas que habitan el campo -que, desde luego, no son exclusivamente varones- pero, a la vez, el campo es mostrado como un lugar para hombres, y la fórmula parece significar entonces "para varones". Por otro lado, ser un hombre de campo no supone únicamente vivir en un contexto rural, sino también desarrollar una serie de destrezas y habilidades, sostener determinadas costumbres y relaciones. De igual manera que un subtema acogió al otro, ser hombre de campo supone estar en condiciones de heredar los valores del gaucho en tanto símbolo de la argentinidad.

Las imágenes de Hombres de Campo componen el paisaje de una sociabilidad masculina. Se encuentran allí escenas de relaciones de hombres entre sí, de ellos con el espacio y el entorno, con animales y plantas, y con mujeres. Las fotografías que muestran grupos de varones son la inmensa mayoría en todos los sobres y cajas a las que envían las fichas del subtema; en el conjunto, representan alrededor del noventa por ciento de las tomas. Las mujeres aparecen muy poco, la mayor parte de los sobres carece de imágenes de mujeres.

Algunas fotografías muestran hombres reunidos en torno a actividades tradicionales de competición más o menos lúdicas, 
como la que congela un momento de una carrera cuadrera, con jinetes sobre sus caballos lanzados a toda velocidad ante la mirada atenta de una fila de otros hombres (Figura 1). La figura 2, por su parte, retrata a una docena de "domadores, en una estancia de la Prov. de Bs. As." hacia 1908, según informa el reverso; los hombres posan ostensiblemente, exhibiendo sus ropas cuidadas, todos con el sombrero puesto, algunos con rastras lujosas, varios con el rebenque en la mano. La fotografía siguiente capta el instante justo en que un hombre con una pierna flexionada y la otra extendida, con el cuerpo levemente inclinado, lanza la taba; otros diez hombres rodean el espacio y siguen los avatares del pequeño hueso, uno alzando una mano en la que enseña el dinero de una apuesta, todos vistiendo rigurosa indumentaria gaucha (Figura 3).

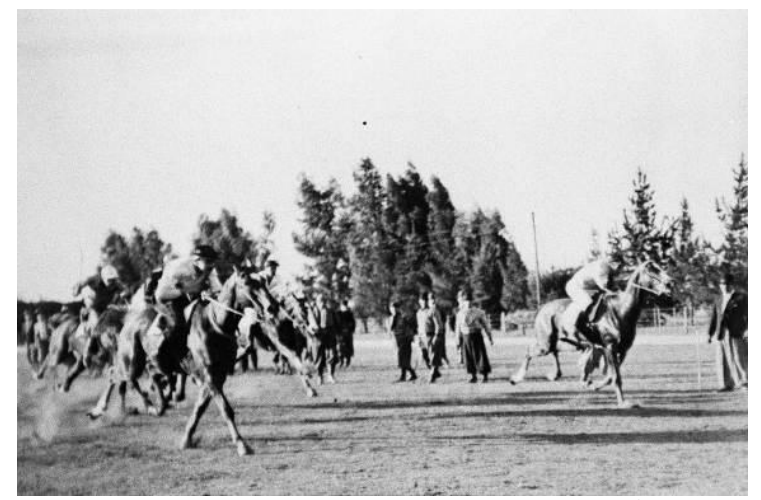

Figura 1. Carrera cuadrera, s/f, AGN. ${ }^{8}$;

\footnotetext{
8 Agradezco al Archivo General de la Nación la autorización para publicar las copias correspondientes.
} 


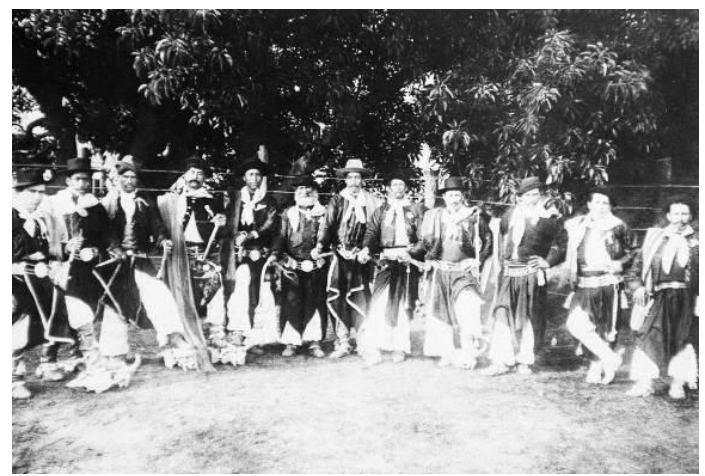

Figura 2. "Domadores", hacia 1908, AGN.

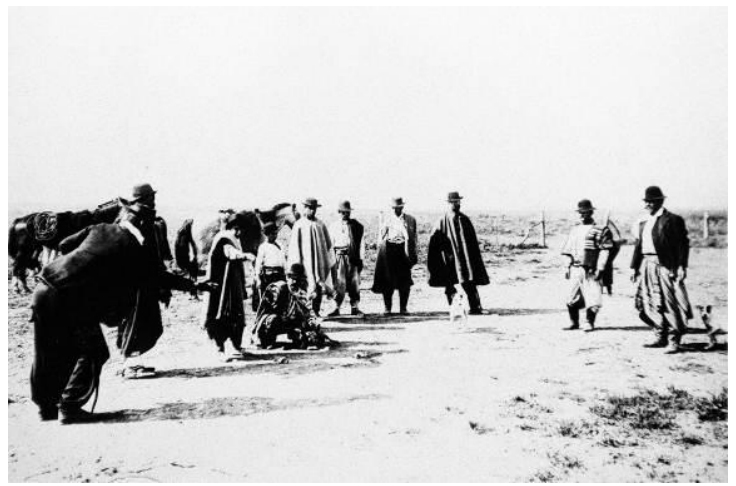

Figura 3. "Jugando a la taba", mediados de s. XIX, AGN.

La mayoría de las fotos del subtema incluye animales. A veces como acompañantes y parte indispensable del entorno, junto con los árboles o la pampa abierta, como en el caso de los perros y caballos en el juego de taba. Otras veces compartiendo el protagonismo con los hombres, como en el caso de los caballos en la cuadrera. Precisamente los caballos, y en segundo lugar las vacas, son los animales que más aparecen en escena, de modo

9 Las comillas indican que el nombre de la figura es aquel que se encuentra en el DDF o parte de alguna de sus leyendas o referencias. 
particular en las situaciones de trabajo. Hombres a caballo rodeando vacas, por ejemplo, en una fotografía de 1936 (Figura 4), hombres que "antes de ensillar al chúcaro" trabajan sobre el animal (Figura 5) y la muy repetida escena de la jineteada: el instante del corcovo del caballo para sacarse al hombre de encima, el jinete que sostiene en el aire las espuelas y el rebenque, antes de caer sobre el animal (Figura 6).

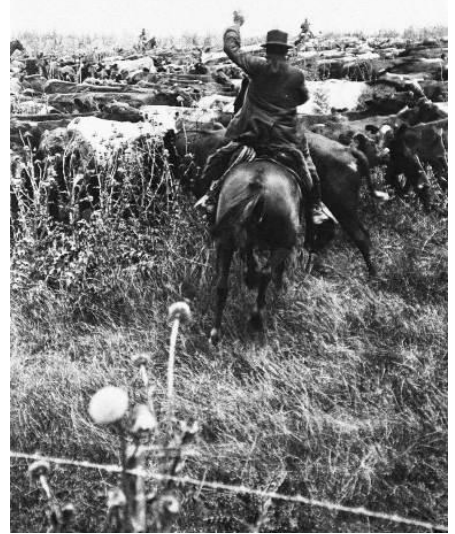

Figura 4. "El rodeo", 1936, AGN.

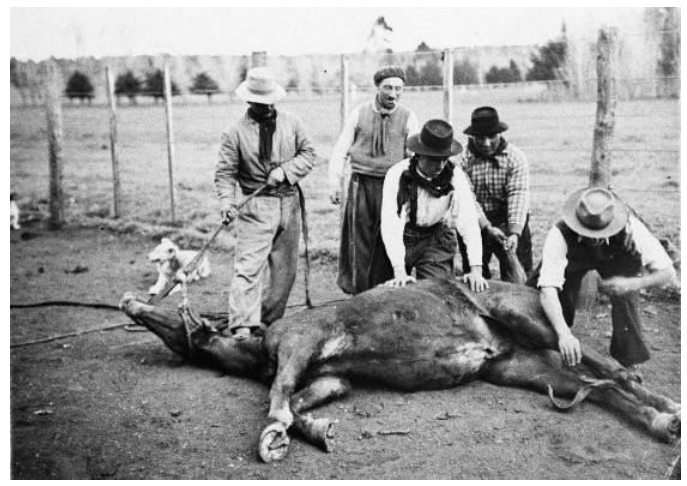

Figura 5. "El chúcaro", 1939, AGN. 


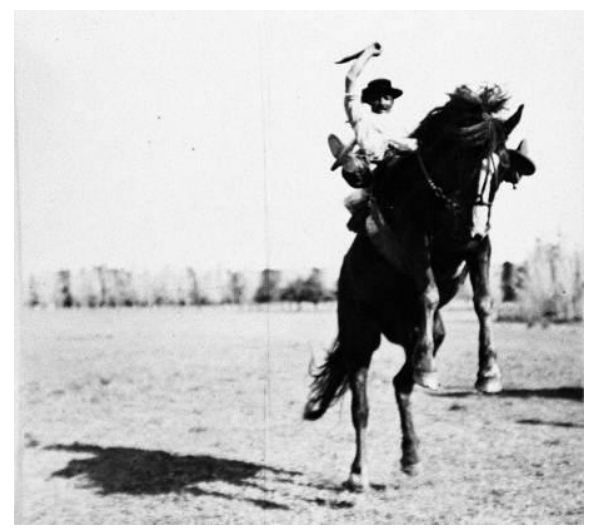

Figura 6. Jineteada, s/f, AGN.

Hombres que se relacionan con hombres y que se relacionan con animales. Hombres que se relacionan entre sí con la mediación de animales. Claramente en el rodeo y en los otros trabajos con animales y sobre animales. También en las fotos de competiciones y juegos, como la carrera cuadrera, y de manera menos patente pero igualmente significativa en las restantes. La foto de los doce domadores evoca a los caballos, y además, si volvemos a ella con atención, veremos que varios de los jinetes alzan sus piernas para apoyar los pies, dominantes, sobre cráneos vacunos. La imagen del juego de la taba, a su vez, muestra a un grupo de hombres que entran en relación con la mediación de un hueso de vaca, lanzado entre ellos y en torno al cual hacen apuestas.

Aunque en menor número, también hay una variedad de fotografías de hombres con vegetación. En ocasiones vuelven a aparecer animales que son utilizados en el trabajo de la agricultura, como en la figura 7, que muestra a un hombre y su caballo haciendo avanzar un aporcador por el surco. La foto siguiente retrata a "un paisanito" que poda cuidadosamente una planta (Figura 8) y la posterior a un "hombre cortando leña", justo cuando levanta el hacha que hará caer sobre el árbol (Figura 9). 


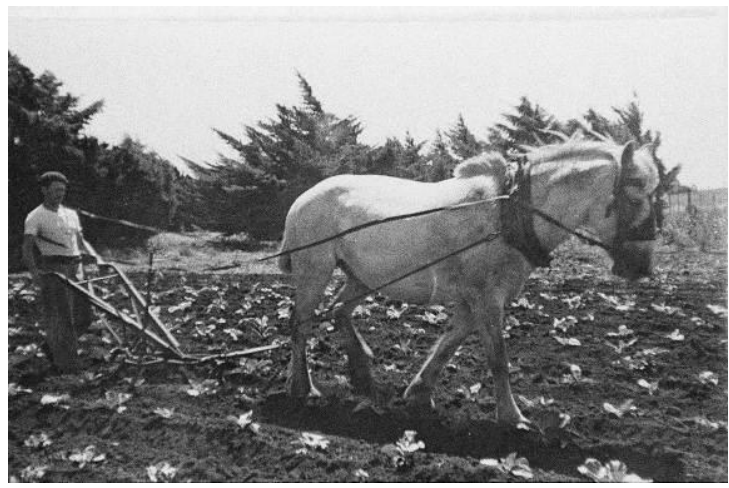

Figura 7. "Hombre trabajando la tierra", s/f, AGN.

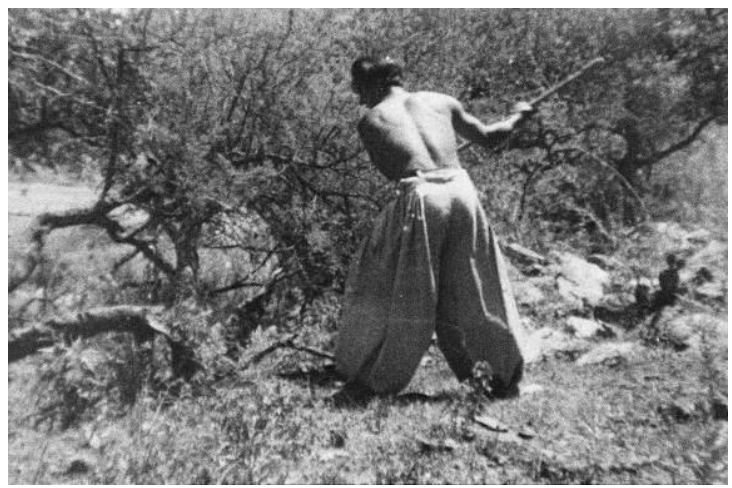

Figura 8. "Un paisanito", s/f, AGN.

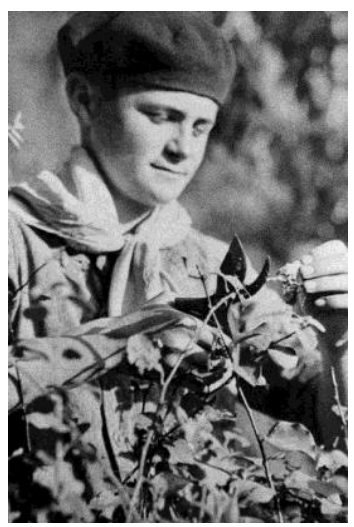

Figura 9. "Hombre cortando leña", s/f, AGN 
Todas estas imágenes podrían reunirse bajo un mismo rótulo: la domesticación de la naturaleza. Y esto parece clave en Argentina, que ha hecho de la naturaleza "el centro de sus autorrepresentaciones políticas, económicas y culturales" (Nouzeilles, 1999:37). Las escenas de amansamiento de animales, de su rodeo y arreo apuntan en esta dirección de manera manifiesta. De la misma manera lo hacen fotografías de otras acciones que no fueron reproducidas aquí, como cazar, enlazar vacas, voltearlas y marcarlas, encerrar o acorralar el ganado o tusar caballos. También son imágenes de domesticación de la naturaleza las del trabajo sobre ella para hacerla producir y para aprovechar sus frutos. Junto a las de agricultura que vimos (labrar la tierra, controlar el crecimiento de las plantas) y otras que se concentran en las herramientas respectivas (palas, arados, azadas, tijeras), algunas de la ganadería van en este sentido, como vacunar ovejas o vacas, vigilar las pariciones, revisar las vacas lecheras en el tambo. Las competiciones y juegos también dan cuenta de la domesticación de la naturaleza, bien porque la presuponen: jugar a la taba presupone el aprovechamiento del animal muerto o matado y una carrera de caballos requiere del control de "el chúcaro", o bien porque justamente representan y simbolizan dicha domesticación: la jineteada es el ejemplo por antonomasia.

Al lado de la abrumadora cantidad de fotos de varones las mujeres están casi ausentes. La desproporción afecta incluso secciones como "Comidas Típicas" y "Cocina", contra lo que expectativas cándidas podrían prever. Allí también hallamos al hombre de campo. Las fotografías de comidas pueden agruparse en dos conjuntos. El primero está en el sobre "Comidas Criollas", que reúne una serie de fotos que parecen pertenecer a una colección ya que tienen numeración de inventario correlativa y, con variaciones irrelevantes, las mismas inscripciones en el reverso, que señalan "La Mujer y la casa. Pdo. 1971", "Cocina Gaucha" y luego el nombre de un plato, como "humitas", "puchero" o "empanadas". Cada fotografía muestra desde arriba, ocupando todo el cuadro, un plato de comida en una mesa, con 
los respectivos cubiertos. Son fotos de la cocina, no de las cocineras.

El segundo conjunto de imágenes muestra en diversas escenas una "comida típica", o más bien la comida típica a juzgar por la cantidad de imágenes que la repiten. En este caso el foco cae también sobre las personas encargadas de prepararla. Se trata de fotos de asados y de asadores, es decir, de los hombres asando la carne de los animales. Hombres solos o, más comúnmente, acompañados de otros hombres; grupos de hombres conversando en torno a la carne que se cocina frente al fuego o las brasas; espacios abiertos, patios o terrenos, a veces el cielo como fondo, arboledas o parte de alguna construcción como marco (Figura 10). Es, una vez más, la sociabilidad masculina recreándose, y recreándose alrededor de la naturaleza que es domesticada, como sugiere el recorte de prensa añadido en el dorso de la figura 11 al aludir metafóricamente al retratado como "domador de costillares".

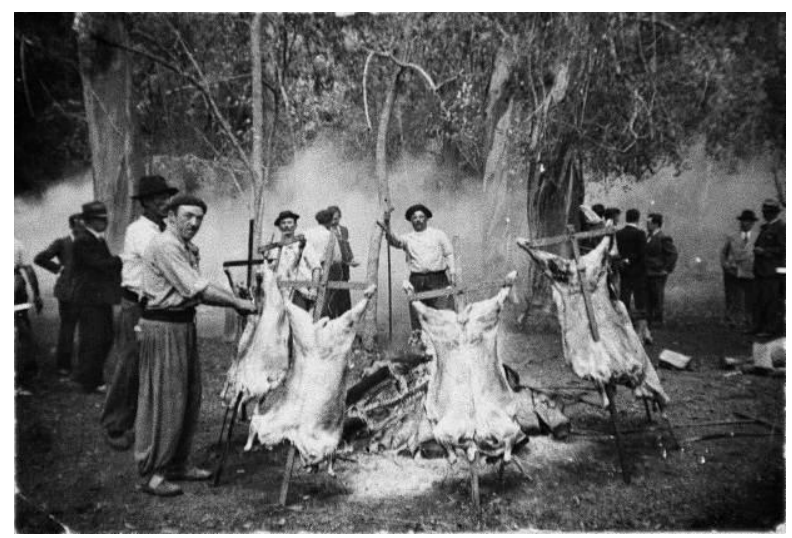

Figura 10. "Escena típica nacional”, 1939, AGN 


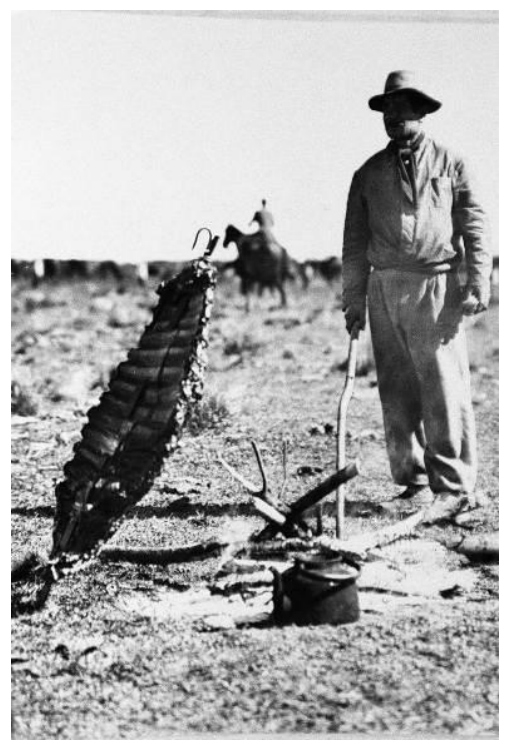

Figura 11. "Domador de costillares", 1939, AGN.

Mujeres, ranchos y hombres de a caballo

Las mujeres solas están casi ausentes, y aun más raras son las tomas de mujeres en grupo. Las dos únicas fotos grupales no cuentan con información escrita. Una retrata cinco mujeres con niñas, detrás de las cuales se ve una especie de toldo o rancho muy pobre. Otra, que muestra un grupo de mujeres en medio del campo, no tiene un encuadre definido, como si fuera resultado de una toma azarosa. Hay otra fotografía de dos mujeres tomando mate en el patio de una casa rural. Con la excepción posible de alguna más, estas son las únicas fotografías de mujeres junto a mujeres dentro de todo el subtema.

Las fotografías individuales de mujeres, por su parte, constituyen también un porcentaje muy pequeño de todo el conjunto, aunque mayor que el de las mujeres en grupo. No hay variedad de imágenes, sino una composición común que reitera, más allá de algunas diferencias, características del encuadre y de la colocación de objetos dentro del mismo: una mujer ubicada de 
frente a la cámara, captada en un plano general que muestra parcialmente el entorno, conformado por una parte de un rancho o un rancho entero, a veces vegetación o animales domésticos o de corral, un horno de barro y, delante de la mujer, un mortero (Figura 12). En este tipo de imágenes, algunas mujeres no están solas, en rigor, sino rodeadas de niños y niñas, como la de la figura 13, rotulada "ranchos". Rancho, entonces, mujer y, a veces, hijos "del" hombre de campo.

Otra de las porciones minoritarias del subtema es la de hombres y mujeres juntos. Las fotografías colocan dos tópicos principales: la visita y la despedida. En el primer caso ponen en imagen un cortejo, tal vez una declaración del gaucho a la mujer, recurriendo a trazos que tienen antecedentes en la pintura costumbrista de mediados del siglo XIX, que tuvo influencia entre algunos de los primeros fotógrafos de Buenos Aires (Alexander; Priamo, 2000). Saliendo del cuadro, o como fondo de dichas fotos, suele verse el caballo ensillado, el hombre como la mujer están de pie, o él de pie y ella sentada, comúnmente bajando la mirada y tomándose a sí misma las manos o bien de espaldas al hombre, expresando quizá pudor o indecisión. En las restantes fotos, las de despedida, los hombres aparecen sobre el caballo yéndose o a punto de irse, mientras la mujer queda atrás, de pie, en el rancho o en la casa, visible total o parcialmente. La mujer mira desde el rancho la partida del hombre, ya más lejos, o bien le alcanza el último mate, en composiciones que reponen el motivo de una foto clásica de Francisco Ayerza, China ofreciendo mate, ella misma en el acervo del AGN (Figura 14). 


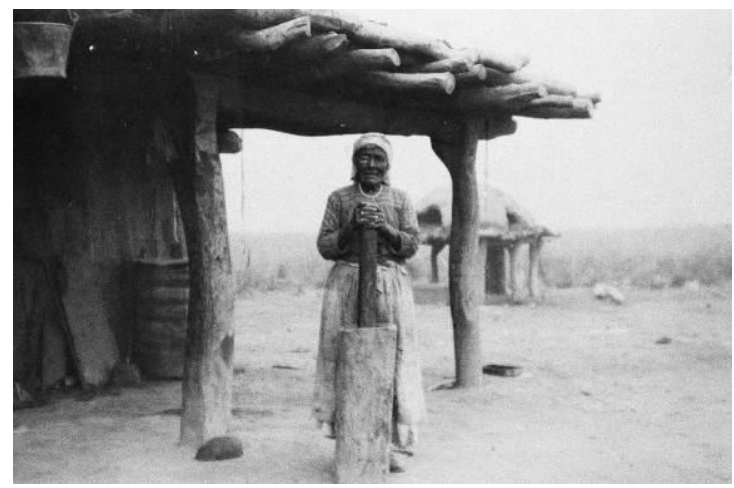

Figura 12. "La pisadora de maíz", 1921, AGN.

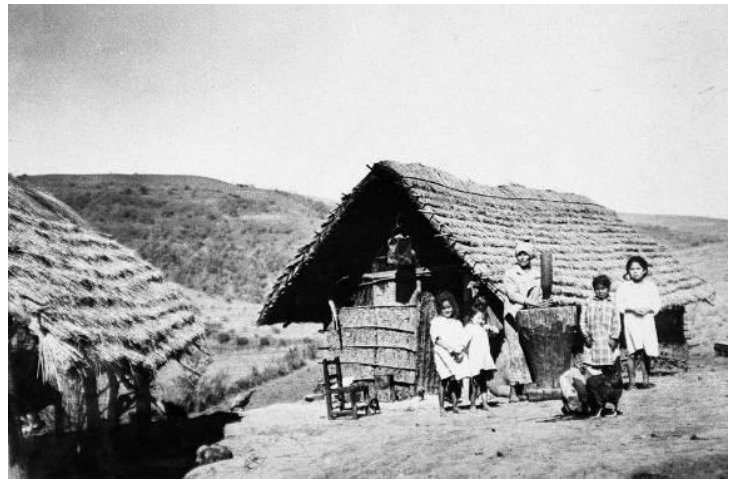

Figura 13. "Ranchos", s/f, AGN.

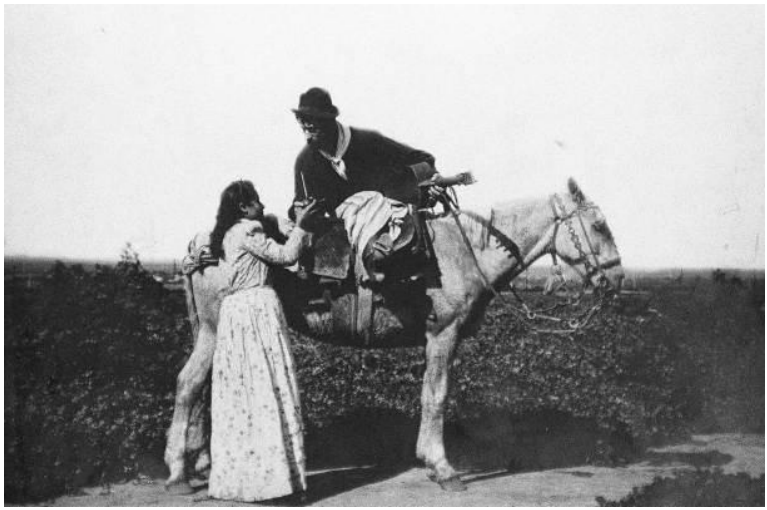

Figura 14. "China ofreciendo mate", Francisco Ayerza, hacia 1900, AGN. 
Si las fotos de hombres con la naturaleza son imágenes de exteriores, lugares abiertos de trabajo, diversión y encuentro, y las fotos de mujeres solas o con niños son imágenes del rancho mismo y su entorno inmediato, las visitas y las despedidas montan visualmente la distinción de los dos ámbitos: el del rancho y el del campo, el de la casa y el del espacio amplio del afuera. La unión de la visita supone (y muestra en la figura del caballo) la separación, y la separación de la despedida se da sobre la unión anterior. Separación y unión de estos ámbitos que, según muestran las imágenes, son realizadas por el hombre de a caballo. El hombre de campo se mueve en ambos lugares y entre ellos.

Por último, cabe detenerse en otras fotografías de hombres que por su cantidad y por la persistencia de su forma constituyen uno de los principales modos de presentación visual del hombre de campo. Son su retrato sin más. Evidencian los componentes necesarios para su representación al mostrar al hombre y su caballo. Con un plano medio o poco mayor se hace foco en la pareja ecuestre y se deja ver también parte del contexto (fs. 15, 16 y 17). La vestimenta varía de acuerdo con la clase social, desde el paisano con alpargatas y bombachas hasta el estanciero con su ropa de montar, pasando por los gauchos con sus prendas "tradicionales". Pero hay numerosos elementos comunes, entre los cuales constituye un dato significativo la exhibición más o menos notoria del rebenque o la fusta. Otro de los elementos reiterado en todas estas imágenes es una de las manos del hombre colocada indefectiblemente en el lomo del caballo, sosteniendo las riendas a la altura de la cruz.

Considero que ese rasgo, siempre respetado en estas fotografías y relacionado con la exhibición del rebenque o la fusta, es una visualización de la propiedad y el control. Es la representación del hombre de campo y su caballo. Las fotografías dan a ver también una suerte de frontera entre adentro y afuera al mostrar una puerta o portón, un alambrado o una tranquera, marcándose así la distinción de esos dos ámbitos entre los cuales el hombre de campo puede moverse. El sentido de la propiedad y el control (o de la propiedad como control) parece extenderse a 
ese entorno de un campo cercado, un rancho o el casco de una estancia. Y en la casa o en el rancho están las mujeres, a veces con niños, de acuerdo con lo que vimos anteriormente. ${ }^{10}$

Vale aclarar que estas composiciones no tienen equivalente en fotografía alguna de mujeres "blancas". Las imágenes de dichas mujeres a caballo en campo abierto son excepcionales $y$, en las existentes, van en ancas del animal. El que dirige el caballo, de manera coherente con lo descripto hasta aquí, es el hombre, que monta delante. ${ }^{11}$

${ }^{10} \mathrm{El}$ desplazamiento de este sentido de propiedad que va del caballo al campo, a la casa y a la mujer puede rastrearse en otros productos culturales y literarios, empezando por el Martín Fierro, obra señera de la literatura nacional: "Tuve en mi pago en un tiempo / hijos, hacienda y mujer" (Hernández, 1979:22); "No tenía mujer ni rancho / y a más era resertor [desertor], / no tenía una prenda güena [buena]/ ni un peso en el tirador" (Hernández, 1979:43, agregados míos). Vale advertir, además, que las ropas, aperos y casas nos muestran las distancias sociales. Los hombres no son igualmente propietarios. Pero, ¿no hay algo en estas imágenes que reúne a los hombres más allá de la desigualdad entre ellos?, ¿no los enlaza masculinamente ese sentido general de la propiedad/control? En esa dirección, ver Berger (1972).

${ }^{11}$ Cabe dejar constancia de un elemento que espera por nuevas exploraciones y mayor profundización: las dos únicas fotografías de mujeres a caballo sin hombre a la vista que pude hallar en Hombres de Campo retratan "indias a caballo", según se indica por escrito en ambos casos, y llevan atavíos mapuche "típicos" o "tradicionales". 


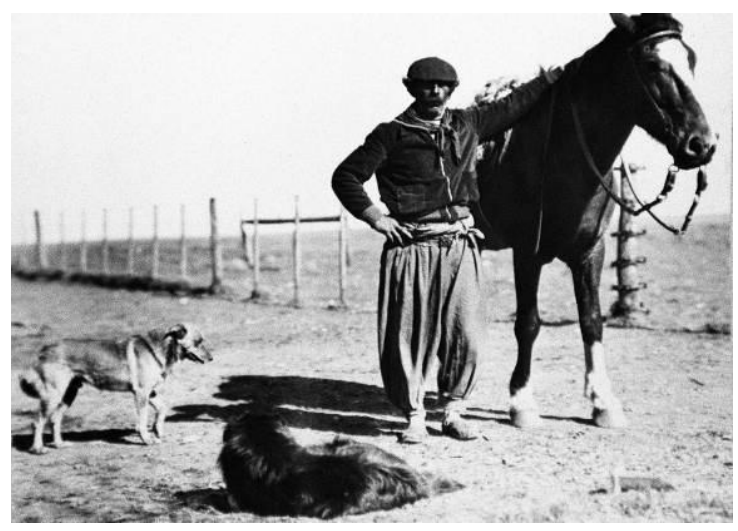

Figura 15. Hombre de campo y su caballo, s/f, AGN.

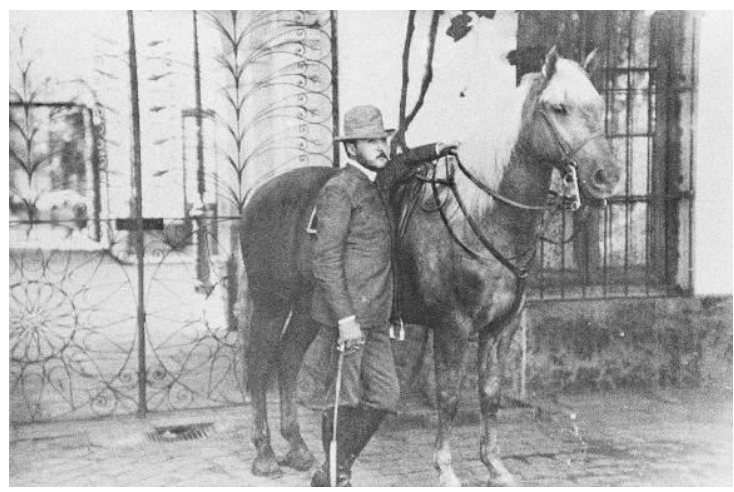

Figura 16. Hombre de campo y su caballo, s/f, AGN. 


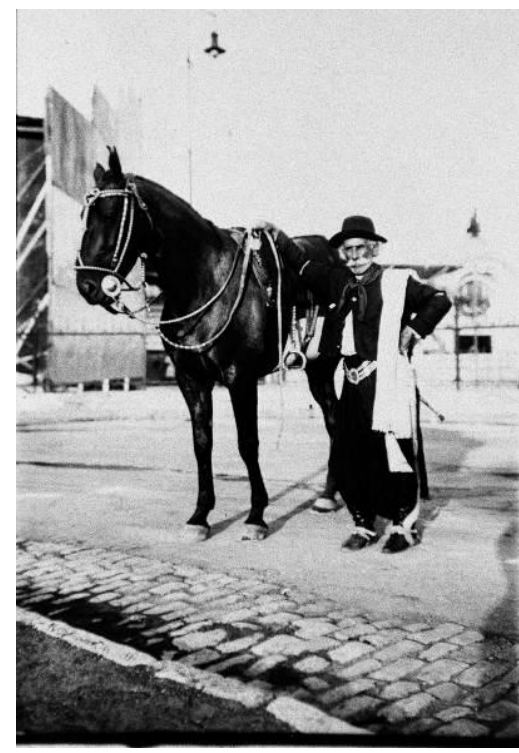

Figura 17. Hombre de campo y su caballo, s/f, AGN.

\section{La domesticación de la naturaleza como tarea masculina y blanca}

Casi la totalidad de las fotografías de hombres del subtema analizado son imágenes de domesticación de la naturaleza y la totalidad de las imágenes de domesticación de la naturaleza son fotografías de hombres. La naturaleza parece ser una materia que aguarda que la mano del hombre (del varón) le dé forma. Parece tratarse de una materia femenina.

Como autoras feministas muestran, en las sociedades occidentales las mujeres "son vistas como más enraizadas en la naturaleza (que los hombres) o teniendo una afinidad más directa con ella" (Ortner, 1996:27), y se les adjudica "el viscoso conglomerado semántico que suele ir adherido al concepto de naturaleza como aquello que, por serlo, debe ser controlado, domesticado y promocionado por la cultura" (Amorós, 1995:160). La compleja imbricación tiene dos caras: a la naturalización de la mujer le corresponde la feminización de la naturaleza. 
Esta segunda cara puede apreciarse en algunos análisis históricos de la conformación del moderno Estado-nación argentino en los años que antecedieron a la formación del Archivo General, una de las instituciones que serían el corolario de esa configuración estatal. La progresiva consolidación del Estado nacional centralizado en Buenos Aires desde que esta se impusiera a las provincias de la Confederación Argentina en 1862 dio lugar a la instalación de una idea significativa, la del "desierto fecundable", que vino a reemplazar la idea anterior del "desierto estéril" (Navarro Floria, 2002). La ingente ampliación de la superficie de explotación agropecuaria posibilitada por la avanzada militar sobre los indígenas una década y media después fue antecedida por y acompañada de una "construcción ideológica de los territorios de la Pampa y la Patagonia" (Navarro Floria, 2002:142) que giró en gran medida en torno de aquella idea del "desierto fecundable". En un análisis del discurso parlamentario de 1862 y 1863, el autor reconstruye cómo el espacio que se había concebido hasta entonces como yermo pasaba a ser considerado un "territorio que la civilización (conquistaría) con la aplicación de un capital a los productos de la tierra" (Diario de Sesiones Diputados de la Nación, 1863, citado por Navarro Floria, 2002:147). Civilización, entonces, y capital para fecundar una naturaleza que dejaría así de ser estéril.

En otro trabajo, esta vez sobre textos del naturalista y escritor argentino británico William Henry Hudson, Navarro Floria advierte explícitamente, aunque no sea el foco de su análisis, el componente de feminización de la naturaleza que albergaban los discursos de la época. Analizando el capítulo "La guerra con la Naturaleza" del libro Días de ocio en la Patagonia (1893), identifica en las páginas de Hudson

el enorme placer que produce en el varón pionero el sometimiento -la violación y fecundación- de una naturaleza imaginariamente feminizada, "inconstante $y$ caprichosa, difícil de gobernar; una hermosa y cruel ondina 
[...] cuyo descubrimiento nos llena de satisfacción" (Navarro Floria, 2004:8). ${ }^{12}$

Con una intelección similar, Nouzeilles cita a Döering, uno de los geógrafos que acompañó a Roca en su campaña militar, quien imaginó un acueducto que llegaría hasta las tierras ganadas a los indígenas y que "distribuir[ía] la bendición de sus aguas fecundas" en forma de "tesoros que el terreno virgen de lo que fue un desierto proporciona[ía] (a los hombres) como recompensa merecida a sus manos laboriosas" (Döering y Lorentz 1939, citado en Nouzeilles, 1999:40). El fragmento muestra que la idea de la naturaleza fecundable había avanzado desde el desierto pampeano al patagónico y también, lo que es más relevante aquí, que la idea tenía vigencia en el momento mismo en que se fundaba el Archivo Gráfico de la Nación que luego se convertiría en el DDF, ya que el texto de Döering y Lorentz sobre la expedición de 1879 fue publicado precisamente en 1939.

\section{Los Aborígenes no son hombres de campo}

La comprensión de que esta domesticación de la naturaleza es, además de masculina, civilizatoria y blanca, estatal y capitalista, invita a revisar otras imágenes del DDF, las de los Aborígenes. Por cierto, los indígenas del archivo no están en la ciudad, con escasas excepciones de fotografías que retratan la visita de dirigentes a algún centro urbano, comúnmente a fin de elevar reclamos o reivindicaciones. Las imágenes que guarda el AGN los muestra casi indefectiblemente en entornos "naturales", a cielo abierto en ámbitos que bien podrían calificarse como rurales. Pero no son hombres de campo, no están reunidos en este

\footnotetext{
${ }^{12}$ Coronil ha mostrado que en la teoría social y económica europea de la época también dominaba la representación de un mundo dividido entre un orden masculino y creativo ligado al capital metropolitano y uno feminizado y pasivo ligado a la naturaleza de la periferia que esperaba la fecundación de aquel (Coronil, 2013).
} 
subtema ni son calificados como tales en las fichas y los dorsos de las fotos. Y además, sus imágenes no muestran lo que muestran las de los Hombres de Campo.

Sin pretender un detalle exhaustivo, además de los que han ido a la ciudad, dentro de Aborígenes se encuentran retratos individualizados de "caciques", miembros de sus familias y alguna "caciquesa", grupos de "indios pacificados" e "indios amigos", muchas veces rodeados de generales del ejército, en ocasiones exhibiendo una destreza o una peculiaridad, ceremonias rituales y otras prácticas, muestras de su cultura material, como artesanías, cementerios, etc.

Dos son las mayores diferencias que el DDF muestra entre los Aborígenes y los Hombres de Campo. Una es que, a pesar de aparecer en contextos naturales, casi no se los ve realizando tareas de "domesticación de la naturaleza". El tipo de actividades con plantas y animales registradas en Hombres de Campo, particularmente las productivas, no tiene lugar entre las imágenes de Aborígenes. La otra diferencia es que, contra toda previsión relativamente informada acerca de la incorporación del caballo por parte de los pueblos nativos, los aborígenes del DDF no montan caballos. Más aún, el contrapunto con Hombres de Campo permite reparar en que numerosos indígenas, varones y mujeres, son mostrados sentados, y varios de ellos acuclillados en el suelo (Figura 18), posición en la que no he hallado retratados a los hombres de campo. 


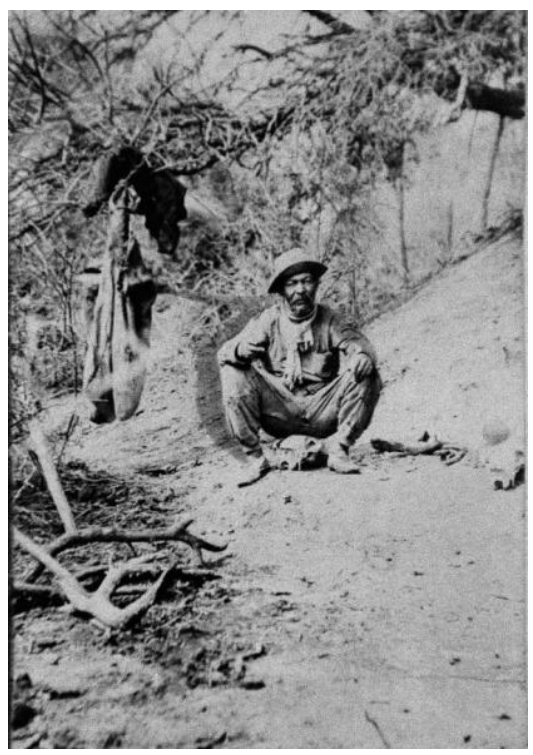

Figura 18. "Aborigen”, AGN.



Figura 19. "Un buen rastreador en la Sierra", "Tipo indígena", AGN.

Hay zonas de ambigüedad que la presencia o ausencia del caballo ayudan a zanjar. El hombre de la figura 19 viste una muy modesta indumentaria básica de gaucho: sombrero, poncho, chiripá. La falta de caballo $-\mathrm{y}$, sin duda, también de calzadopodrían ser las causas de su identificación como "tipo indígena". Entre fotografías menos despojadas o fotografiados menos pobres también se dibujan zonas de ambigüedad. Los hombres de las figuras 20 y 21 se parecen entre sí. Son semejantes sus rostros y sus barbas canosas debajo de sus sombreros también parecidos. Los dos llevan estricta indumentaria gaucha: bombachas, botas, pañuelo uno, poncho el otro. Ni un criterio fenotípico ni las vestimentas podrían ser la causa de que uno sea clasificado como "un viejo gaucho" y otro como miembro de una "familia de aborígenes". El caballo ensillado y montado del primero sí puede haber sido definitorio para ello. 




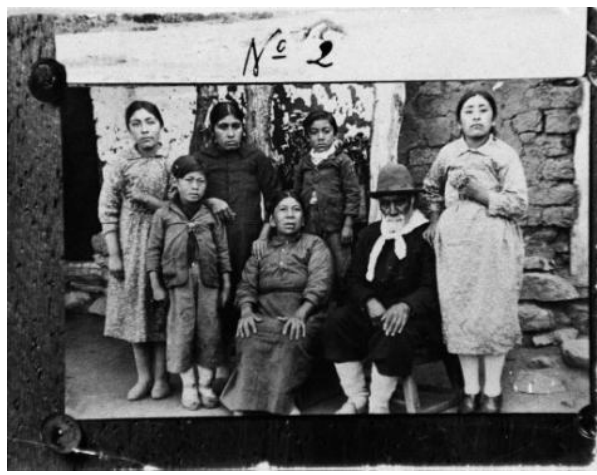

Figura 21. "...una familia de aborígenes", AGN.

Figura 20. "Un viejo gaucho...", AGN.

La domesticación de la naturaleza que caracteriza al hombre de campo, emblema de la argentinidad, conlleva y sustenta una configuración de género. Está cargada de valores que distribuyen roles y tareas e imaginan, sobre todo, una capacidad desigual de control y de dominio. Simultáneamente, la masculinidad del hombre de campo en el archivo se desmarca de cualquier posible confusión con la presencia indígena en el campo. Los aborígenes no son hombres de campo porque no se relacionan con la naturaleza de la manera en que aquellos lo hacen. La masculinidad que controla la naturaleza y puede fecundarla conecta con una historia nacional y carga con ella: la de los blancos que en nombre del Estado avanzaron sobre el mundo salvaje. La domesticación de la naturaleza es masculina, blanca y civilizatoria. 


\section{La figura emblemática y la distribución de espacios sociales}

La composición visual del "hombre de campo" pone en escena la división entre un mundo del afuera, del espacio abierto, de los pares y de la producción y un mundo del adentro, del hogar, los niños y la reproducción, entre los trabajos del campo y las actividades tradicionales, por un lado, y la esfera del rancho y la domesticidad, por otro. Estos ámbitos separados, que solo el hombre sería capaz de unir, son presentados respectivamente como instancia de encuentros y asociación, y como instancia de soledad o compañía infantil.

Siendo que, como algunas especialistas han notado, la configuración moderna de lo público y lo privado, y la correspondiente construcción de la esfera privada como femenina, se dan en un contexto urbano, cuando entre finales del siglo XIX y comienzos del XX la ascendiente clase media postula la interioridad como su esencia y virtud (Smith, 1999; Poole, 2000), cabe preguntarse en qué medida no asistimos aquí a la proyección de este tipo de valores y de esta separación de espacios desde el mundo urbano y moderno de Buenos Aires, en que se definía el orden del archivo, hacia los materiales que eran clasificados, el mundo rural incluido.

Tanto el confinamiento de las mujeres al trabajo doméstico como, igualmente, la desvalorización de éste (y de sus encargadas) han recibido críticas sistemáticas en los estudios feministas desde hace por lo menos cuarenta años (Stolcke, 1982). También se ha mostrado la necesidad de revisar conceptualmente dicha división y se ha cuestionado la universalidad de la misma (Fraser, 1997; Benhabib, 2002). Por ello no deja de resultar sumamente significativa su reiteración, su persistencia más o menos sorda a las innumerables críticas que ha recibido y a las transformaciones históricas que la afectaron.

Como apunté, pautas consuetudinarias y reglas de funcionamiento que implican no modificar la organización de un archivo cuando es recibido determinan una gran estabilidad en el ordenamiento del acervo del AGN. La mayoría de las entradas del 
Índice Temático son antiguas y parecen proceder de la creación misma del archivo. En este marco de continuidad, no obstante, el archivo muestra ser un espacio lleno de vida (Jelin, 2002), donde se constatan reenvíos de un tema a otro, reagrupamientos, correcciones y añadidos en las descripciones y las indexaciones. El cambio de nominación referido en la nota 4 es un buen ejemplo de ello. Pero respecto de la división generizada de espacios sociales en Hombres de Campo la estabilidad parece haber sido una norma estricta.

Estas imágenes enseñan que el mundo del afuera constituido por el campo abierto no es para mujeres. Y tal división de espacios aparece sostenida por la apropiación masculina de una naturaleza que es presentada como materia prima a ser domesticada. Solo los varones son vistos como quienes conectan con sus recorridos los espacios separados del afuera y el adentro, precisamente por su control del entorno natural, es decir, por su apropiación de una naturaleza que domestican. De ahí el singular peso que la pareja ecuestre adquiere en la construcción visual del mundo rural. El caballo, a la vez ejemplo de la domesticación y apertura a ámbitos no domésticos, aparece como pareja inseparable del hombre ("blanco").

\section{Conclusiones}

Las representaciones de género que se despliegan alrededor de los hombres de campo coinciden con las convenciones sociales que han hecho que la presencia de hombres y la de mujeres sean distintas en la historia visual occidental. Según Berger, si la presencia de la mujer parece emerger como intrínseca a su persona, casi como una emanación física, el hombre es habitualmente mostrado como promesa de un poder (moral, físico, económico, sexual u otro), cuyo objeto es externo (Berger, 1972). También Mira ha destacado que la imagen de los hombres se ofrece no como cuerpo, sino como acción que recaerá sobre su exterior (Mira, 2003). A su vez, en una reflexión sobre la fotografía de paisajes, Bright señala que, según una mirada masculina 
(blanca y de clase media), "los hombres eligen interactuar con la naturaleza y someterla a su voluntad, mientras que las mujeres simplemente son la naturaleza y no pueden definirse a sí mismas en oposición a ella" (Bright, 1992:138). El hombre de campo en las imágenes del AGN hace cosas, proyecta su acción sobre el entorno, sobre la naturaleza y los seres que a ella pertenecen o que le están más próximos y los transforma, domestica, controla, civiliza.

Como señalara Descola (2005), el naturalismo supone no solo concebir la existencia de la naturaleza, sino también postular como su contraparte una esfera de libertad. La forma concreta que toma aquí el naturalismo es la atribución diferencial de naturaleza y libertad a mujeres y a hombres respectivamente. El control de la naturaleza y el manejo de los espacios sociales y del entorno cae claramente dentro de la órbita masculina. En síntesis, la feminización de la naturaleza reserva al varón la capacidad de acción cultural de control sobre ella. Esta capacidad se presenta como trazo distintivo de este emblema masculino de la argentinidad y sostiene la distinción de tareas y ámbitos presuntamente propios de varones y mujeres.

Pero además, esta capacidad se visualiza sobre el presupuesto de que esos varones son blancos. El gaucho es una figura blanca o, más precisamente, es una figura que en sus representaciones se ha ido blanqueando a lo largo de la historia. Otros habitantes que puedan compartir su espacio no son registrados visualmente con una capacidad equivalente de acción sobre el entorno natural: ni las mujeres, como vimos, ni los indígenas.

Las relaciones de género, como todas las relaciones sociales, intersectan diferentes dimensiones de la diferencia y la desigualdad (Stolcke, 1992). Las imágenes del DDF son un terreno propicio para plasmar esas intersecciones. La sola distinción de categorías a partir de la que se erige Hombres de Campo como tal implica algo que no debe pasar desapercibido: la distinción asume que las fotografías de hombres de campo no muestran aborígenes ni negros, las de Aborígenes no muestran hombres de campo ni negros, etc. Es decir, los hombres de campo no son aborígenes ni 
negros... y así siguiendo. Y la visualización positiva de unos y otros se distancia precisamente a propósito del poder de control sobre la naturaleza salvaje que cada uno ostenta. La caracterización del gaucho $\mathrm{u}$ hombre de campo en el archivo requiere de relaciones específicas no solo con las mujeres "blancas", sino también con hombres y mujeres indígenas.

Un archivo visual nacional que se estructuró en el segundo cuarto del siglo XX mostró la mano del hombre (del varón) que había domesticado la naturaleza. La naturaleza - una parte de ellaresultó ser campo como producto de esa domesticación, un campo que se civilizaba por esta presencia del hombre (presuntamente blanco). Al mostrarlo, las imágenes del archivo también blanqueaban el campo.

$\mathrm{Su}$ permanencia da cuenta de una inercia compleja. Razones técnicas, como la regla de conservar el orden de procedencia de los documentos, están evidentemente habitadas por configuraciones culturales patriarcales y blancas que ponen límites y presiones (Williams, 2000) a los modos de mostrar y de ver (y de no ver). Imágenes de indígenas (o de negros) como hombres del campo argentino podrían teñir la idealizada piel blanca (que es la blanqueada piel ideal) del emblemático gaucho. Imágenes de mujeres blancas (o indígenas o negras) en ese campo, trabajándolo o incluso "civilizándolo", podrían feminizar un ámbito masculino constitutivo del Estado nacional y de una forma de la argentinidad.

\section{Referencias bibliográficas}

Alexander, Abel; Priamo, Luis. Buenos Aires. Ciudad y Campaña 1860/1870. Fotografías de Esteban Gonnet, Benito Panunzi y otros. Buenos Aires, Fundación Antorchas, 2000.

Amorós, Celia. Hacia una crítica de la razón patriarcal. Barcelona, Anthropos, 1995.

APPADURAI, Arjun. La modernidad desbordada. Dimensiones culturales de la globalización. Buenos Aires, Trilce/Fondo de Cultura Económica, 2001. 
ARCHETTI, Eduardo. Hibridación, pertenencia y localidad en la construcción de una cocina nacional. In: Altamirano, Carlos (ed.). La Argentina del siglo XX. Buenos Aires, Ariel, 1999, pp.217-237.

BARRANCOS, Dora. Mujeres, entre la casa y la plaza. Buenos Aires, Sudamericana, 2008.

BARTHES, Roland. Lo obvio y lo obtuso. Imágenes, gestos, voces. Barcelona, Paidós, 1986.

BENHABIB, Seyla. The claims of culture: Equality and diversity in the global era. Princeton, Princeton University Press, 2002.

BERGER, John. Ways of seeing. London, British Broadcasting Corporation and Penguin Books, 1972.

BORGES, Jorge Luis. Obras Completas (Otras Inquisiciones, 1952). Buenos Aires, Emecé Editores, 1989.

BRIGHT, Deborah. Of Mother Nature and Marlboro Men: An Inquiry into the Cultural Meanings of Landscape Photography. In: BOLTON, Richard (ed.), The Contest of Meaning: Critical Histories of Photography. Massachussetts, The MIT Press, 1992, pp.125-143.

CAggiano, Sergio. El sentido común visual. Disputas en torno a género, "raza" y clase en imágenes de circulación pública. Buenos Aires, Miño y Dávila Editores, 2012.

CAgGiano, Sergio. Conservar el vacío. Imágenes de la desaparición de los negros en el Archivo General de la Nación. Corpus. Archivos virtuales de la alteridad americana, vol. $6, \mathrm{n}^{\circ} 2$, Mendoza, Julio Diciembre 2016, pp.1-16 [http://corpusarchivos.revues.org/1740].

CORONIL, Fernando. El estado mágico: naturaleza, dinero y modernidad en Venezuela. Caracas, Alfa, 2013.

Da Silva Catela, Ludmila. El mundo de los archivos. In: DA SILVA CATElA, Ludmila; Jelin, Elizabeth (comp.). Los archivos de la represión: Documentos, memoria y verdad. Madrid, Siglo XXI, 2002, pp.195-219.

DamatTA, Roberto. A Casa \& a Rua. Rio de Janeiro, Rocco, 1997.

DERNÉ, Steve. Men's sexuality and women's subordination in Indian nationalisms. In: MAYER, Tamar (ed.). Gender ironies of nationalism. London, Routledge, 2000, pp.237-259. 
DESCOLA, Philippe. Más allá de la naturaleza y la cultura. Etnografías Contemporáneas, 1 (1), Buenos Aires, 2005, pp.93-114.

DiDI-HubERMAN, Georges. Das Archiv brennt. In: DiDI-HuBERMAN, Georges; EBELING, Knut (ed.). Das Archiv brennt, Berlin, Kadmos, 2007, pp.7-32.

FARGE, Arlette. Le goût de l'archive. Paris, Éditions du Seuil, 1989.

FouCAult, Michel. La Arqueología del Saber. México, Siglo XXI, 1991.

FRASER, Nancy. Iustitia Interrupta. Reflexiones críticas desde la posición "postsocialista". Bogotá, Siglo del Hombre Editores-Universidad de los Andes, 1997.

GOFFMAN, Erving. La ritualización de la femineidad. In: GofFMAN, Erwing, Los momentos y sus hombres. Textos seleccionados y presentados por Yves Winkin. Barcelona, Paidós, 1991, pp.135-168.

GOMES DA CUNHA, Olívia. Intenção e Gesto: pessoa, cor e a produção cotidiana da (in)diferença no Rio de Janeiro, 1927-1942. Rio de Janeiro, Arquivo Nacional, 2002.

. Do ponto de vista de quem? Diálogos, olhares e etnografias dos/nos arquivos. Estudos Históricos, 36, Rio de Janeiro, 2005, pp.732 .

HenG, Geraldine; Devan, Janadas. State Fatherhood: The Politics of Nationalism, Sexuality, and Race in Singapore. In: PARKER, Andrew et alii (ed.). Nationalism \& Sexualities. London, Routledge, 1992, pp.343-364.

HERNÁNDEZ, José. Martín Fierro (El gaucho Martín Fierro y La vuelta de Martín Fierro). Buenos Aires, Centro Editor de América Latina, 1979 [1872 y 1879].

JELIN, Elizabeth. Introducción. Gestión política, gestión administrativa y gestión histórica: ocultamientos y descubrimientos de los archivos de la represión". In: DA SILVA CATELA, Ludmila; JELIN, Elizabeth (comp.). Los archivos de la represión: Documentos, memoria y verdad. Madrid, Siglo XXI, 2002, pp.1-13.

LUDMER, Josefina. El género gauchesco. Un tratado sobre la patria. Buenos Aires, Perfil libros, 1994. 
MIRA, Maria Celeste. O masculino e o feminino nas narrativas da cultura de massas ou o deslocamento do olhar. cadernos pagu (21), Campinas-SP, Núcleo de Estudos de Gênero-Pagu/Unicamp, 2003, pp.13-38.

NAVARRO FlORIA, Pedro. William H. Hudson en la naturaleza patagónica (1870 y 1893): último viajero científico y primer turista posmoderno. Theomai 2004, [http://www.redalyc.org/articulo.oa?id=12401003 acceso en: 15 enero 2018].

NAVARRO-FloRIA, Pedro. El desierto y la cuestión del territorio en el discurso político argentino sobre la frontera Sur. Revista Complutense de Historia de América, 28, 2002, pp.139-168.

MONTALDO, Graciela. De pronto, el campo: Literatura argentina y tradición rural. Rosario, Beatriz Viterbo, 1993.

NouzEILlES, Gabriela. Patagonia as Borderland: Nature, Culture, and the Idea of the State. Journal of Latin American Cultural Studies, 8(1), 1999, pp.35-48.

ORTNER, Sherry. Making Gender: The Politics and Erotics of Culture. Boston, Beacon Press, 1996.

Poole, Deborah. Visión, raza y modernidad. Una economía visual del mundo andino de imágenes. Lima, Sur Casa de Estudios del Socialismo y Consejería en Proyectos, 2000.

RADCLIFFE, Sarah; WeSTWOOD, Sallie. Remaking the Nation. London, Routledge, 1996.

RICHARDS, Thomas. The Imperial Archive: Knowledge and the Fantasy of Empire. London, Verso, 1993.

RINESI, Eduardo. Ciudades, teatros y balcones. Buenos Aires, Paraíso, 1994.

SÁBATO, Hilda. La política en las calles: entre el voto y la movilización: Buenos Aires, 1862-1880. Buenos Aires, Sudamericana, 1998.

SAlvatore, Ricardo. Wandering Paysanos: State Order and Subaltern Experience in Buenos Aires during the Rosas Era. New Carolina, Duke University Press, 2003.

SCHAEFFER, Jean-Marie. La imagen precaria. Del dispositivo fotográfico. Madrid, Cátedra, 1990. 
SEKUlA, Allan. The Body and the Archive. October, vol. 39, Massachusetts, 1986, pp.3-64.

SigAl, Silvia. La Plaza de Mayo. Una crónica. Buenos Aires, Siglo XXI, 2006.

SMITH, Shawn Michelle. American Archives. Gender, Race, and Class in Visual Culture. New Jersey, Princeton University Press, 1999.

STOLCKE, Verena. Los trabajos de las mujeres. In: LEÓN, Magdalena (ed.). Debate sobre la mujer en América Latina y el Caribe, vol. III. Sociedad, subordinación y feminismo. Bogotá, ACEP, 1982, pp.1133.

- Racismo y sexismo en la Cuba colonial. Madrid, Alianza Editorial, 1992.

STOLER, Ann Laura. Colonial Archives and the Arts of Governance. Archival Science: International Journal on Recorded Information, 2(2), Kluwer Academic Publishers, Netherlands, 2002, pp.87-109.

Trouillot, Michel-Rolph. Silencing the Past. Power and the Production of History. Boston, Beacon Press, 1995.

VALE DE ALMEIDA, Miguel. Corpos marginais: notas etnográficas sobre páginas "de polícia" e páginas "de sociedade". cadernos pagu (14), Campinas-SP, Núcleo de Estudos de Gênero-Pagu/Unicamp, 2000, pp.129-147.

VIÑAS, David. Literatura argentina y realidad política, vols. 1 y 2. Buenos Aires, Centro Editor de América Latina, 1994.

WiLliAmS, Raymond. Marxismo y Literatura. Barcelona, Península/Biblos, 2000.

ZEMON DAVIS, Natalie. Fiction in the Archives. Pardon tales and their tellers in sixteenth century France. Stanford, Stanford University Press, 1987. 